\title{
NUMERICAL SIMULATION OF THE BEHAVIOR OF AN EXPANSIVE SOIL
}

\author{
L.M. $\operatorname{Costa}^{1}$, S. R. M. Ferreira ${ }^{2}$, I. D. S. Pontes ${ }^{2}$ and L. J. N. Guimarães ${ }^{2}$ \\ ${ }^{1}$ Department of Technology, Federal University of Pernambuco (licia@ufpe.br) \\ ${ }^{2}$ Department of Civil Engineering, Federal University of Pernambuco
}

\begin{abstract}
This paper presents a numerical analysis of the behavior of an expansive soil of the semi-arid region of the northeast of Brazil. The behavior of expansive soils, due to applied stress or suction, is governed by various phenomena occurring at microstructural level. Gens \& Alonso [4] presented a conceptual basis for modeling expansive soil, considering two different levels: the microstructural level, at which swelling of active minerals takes place and the macrostructural level responsible for major structural rearrangement. Based on this conceptual framework and in the improvements suggested by Alonso et al. [2], Sanchez et al. [5] proposed a double structure generalized plasticity model, which was implemented in the computational code CODE_BRIGHT. This paper applies the coupled hydro-mechanical formulation implemented in this code to simulate the behavior of an expansive soil due to changes in water content. Output results of numerical simulations of laboratory tests show a good agreement with experimental data.
\end{abstract}

Keywords: Expansive soil, double structure model, hydro-mechanical coupled analysis.

\section{INTRODUCTION}

Volume change of expansive soils, due to applied stress or suction, is governed by various phenomena occurring at microstructural level, in individual clay particles and their vicinity. Gens \& Alonso [4] presented a conceptual basis for modeling expansive soil considering two different structural levels: the microstructural level, at which swelling of active minerals takes place and the macrostructural level responsible for major structural rearrangement.

This paper presents an application of a double structure model, proposed by Sanchez et al. [5] and implemented in the finite element computational code CODE_BRIGHT to evaluate the behavior of an expansive soil of the semi-arid region of the northeast of Brazil, due to changes in water content.

\section{DOUBLE STRUCTURE MODEL}

The double structure generalized plasticity model proposed by Sanchez et al. [5] was 
based on the general framework presented by Gens \& Alonso [4] and takes into account the improvements suggested by Alonso et al. [2]. The macrostructure behavior is described by the Barcelona Basic Model (BBM) [1]. Other mechanisms, not incorporated in the BBM, which occur in the microstructure, at clay particle level, can take place in expansive soils inducing plastic strains. So the formulation presents the definition of laws for the macrostructural level, the microstructure level and the interaction between both structural levels.

\subsection{Macrostructure model}

BBM considers two independent stress variables, the net stress, $\left(\sigma_{i j}-p_{a} \delta_{i j}\right)$, and matric suction, $s=\left(p_{a}-p_{w}\right)$. It is an elastoplastic strain-hardening model, which extends the concept of critical state for saturated soils to unsaturated conditions including a dependence of the yield surface on matric suction. The yield surface is expressed by

$$
f\left(p, q, s, p_{0}^{*}\right) \equiv q^{2}-M^{2}\left(p+p_{s}\right)\left(p_{0}-p\right)=0 .
$$

with

$$
\begin{gathered}
p=\sigma_{m}-\max \left(p_{a}, p_{w}\right) ; \sigma_{m}\left(\sigma_{1}+\sigma_{2}+\sigma_{3}\right) / 3 . \\
q=\sigma_{1}-\sigma_{3} . \\
p_{s}=k s .
\end{gathered}
$$

where $p$ is the net mean stress, $\sigma_{1}, \sigma_{2}$ and $\sigma_{3}$ are the total principal stress, $M$ is the slope of the critical state line, $p_{0}$ is the apparent unsaturated isotropic preconsolidation stress for suction $s$, $p_{0} *$ is the saturated preconsolidation stress, $k$ describes the increase of the apparent cohesion with suction.

For isotropic conditions yield states associated with suction are described by means of a yield function defined in the space $(\mathrm{p}, \mathrm{s})$, which is named the Loading-Collapse yield surface (LC). It explains the collapse upon wetting and the increase of apparent preconsolidation stress $p_{0}$ with suction through the following relationship

$$
\frac{p_{0}}{p^{c}}=\left(\frac{p_{0}^{*}}{p^{c}}\right)^{\frac{\lambda(0)-\kappa}{\lambda(s)-\kappa}} .
$$

with

$$
\lambda(s)=\lambda(0)[(1-r) \exp (-\beta s)+r]
$$

where $\kappa$ is the elastic stiffness parameter against changes in $p, \lambda(0)$ is the slope of virgin compression line for saturated isotropic loading, $p^{c}$ is a reference stress and $\lambda(s)$ is the slope of virgin compression line for isotropic loading at a constant suction $s$. $\beta$ controls the rate of stiffness increase with suction and $r$ is a limiting value of soil stiffness for very high suction. 
A non associated plastic potential is defined by

$$
g\left(p, q, s, p_{0}^{*}\right)=\alpha q^{2}-M^{2}\left(p+p_{s}\right)\left(p_{0}-p\right) .
$$

where $\alpha$ is established in such a way that under $K_{0}$ loading lateral strains are zero.

The hardening parameters, $p_{0} *$ depends on the rate of volumetric plastic strain. The hardening law is given by

$$
\frac{d p_{0}^{*}}{p_{0}^{*}}=\frac{(1+e)}{\lambda(0)-\kappa} d \varepsilon^{p}
$$

where $e$ is the void ratio.

Elastic strains are induced by changes in net mean stress, deviatoric stress and suction according to

$$
d \varepsilon^{e}=\frac{\kappa}{(1+e)} \frac{d p}{p}+\frac{1}{3 G} d q+\frac{\kappa_{s}}{(1+e)} \frac{d s}{\left(s+p_{a t m}\right)}
$$

where $G$ is the shear modulus, $\kappa_{s}$ is the elastic stiffness parameter against changes in suction and $p_{a t m}$ is the atmospheric pressure.

\subsection{Microstucture model}

The microstructural behaviour is assumed elastic and volumetric. The microstructural volumetric strain depends on a microstructural effective stress $(\hat{p})$ defined by

$$
\hat{p}=p+\chi s
$$

where $\chi$ is a constant.

Another assumption adopted in this formulation is the hydraulic equilibrium between microstructure and macrostructure, thus only one suction variable should be considered.

In the $(p, s)$ plane, a line corresponding to a constant microstructural effective stresses is named neutral line (NL), since no microstructural strain takes place along it. The neutral line divides the $(p, s)$ plane into two parts, defining a compression microstructural stress path and a swelling microstructural stress path, as indicated in figure 1.

The increment of the microstructural elastic strain is expressed as a function of the increment of the microstructural effective stress as

$$
\dot{\varepsilon}_{v m}=\frac{\dot{\hat{p}}}{K_{m}}=\frac{\dot{p}}{K_{m}}+\chi \frac{\dot{s}}{K_{m}} .
$$

where the subscript $\mathrm{m}$ refers to the microstructural level, the subscript $v$ refers to the volumetric component and $K_{m}$ is the microstructural bulk modulus, that in this paper is computed by the following law 


$$
K_{m}=\frac{e^{-\alpha_{m} \hat{p}}}{\beta_{m}} .
$$

Microstructural effects induce irreversible macrostructural deformations, which are considered proportional to microstructural strain according to interaction functions.

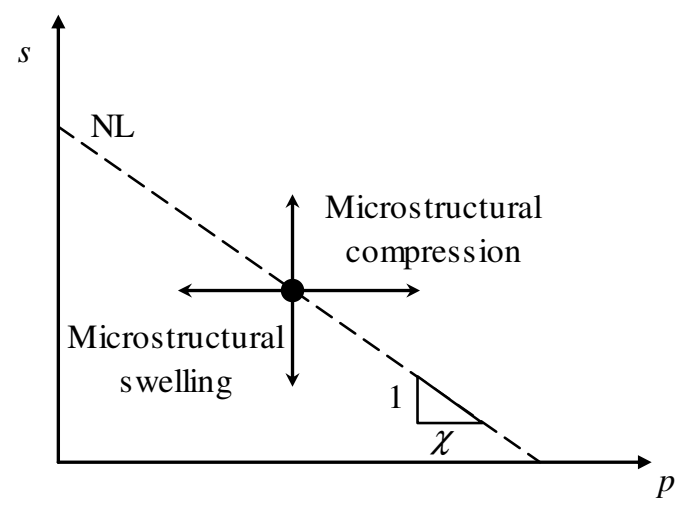

Figure 1. Definition of microstructural swelling and contraction paths.

\subsection{Interaction functions}

Two interaction functions are definided: $f_{c}$ for microstructural compression paths and $f_{s}$ for microstructural swelling paths. For isotropic loading the interaction functions depend on the ratio $p / p_{0}$.

The ratio $p / p_{0}$ indicates the degree of openness of the macrostructure relative to the applied stress state. When this ratio is low it means a dense packing of the material and it is expected that microstructural swelling induces large macrostructural plastic strains.

According to Alonso et al. [2] any suitable function for $f_{s}$ and $f_{c}$ consistent with the physical ideas presented in Figure 2 can be adopted.

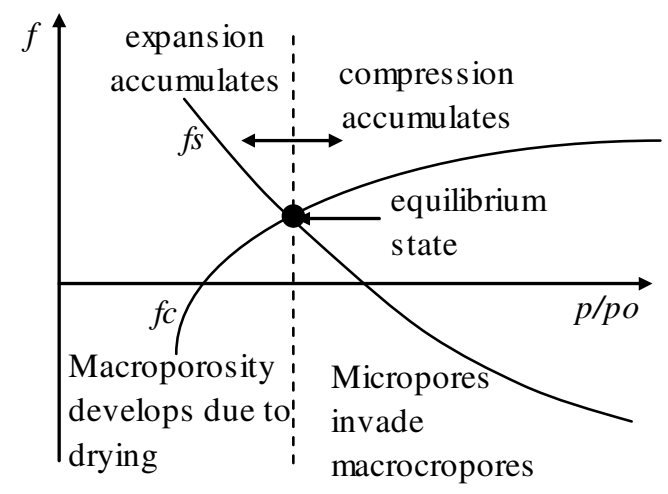

Figure 2. Interation mechanisms between micro and macropores.

In this paper the interaction functions are expressed by

$$
f_{s}=f_{s 0}+f_{s 1}\left(p / p_{0}\right)^{n_{s}} .
$$




$$
f_{c}=f_{c 0}+f_{c 1}\left(p / p_{0}\right)^{n_{c}}
$$

\section{NUMERICAL SIMULATION}

The model described above was implemented in the finite element computational code CODE_BRIGHT and was applied to simulate laboratory tests performed with an expansive soil of the semi-arid region of the northeast of Brazil.

In order to evaluate the behavior of an expansive soil due to changes in water content, Ferreira \& Ferreira [3] performed a series of oedometric tests with samples at different initial water content. Changing in natural water content was performed taking the samples to desiccators and moistening or drying them. At natural water content the soil presented the following characteristics: $\mathrm{w}_{\mathrm{L}}=60 \%, \mathrm{PI}=30 \%, \mathrm{w}_{\mathrm{c}}=19 \%, \mathrm{w}=17.41 \%$ and $\gamma_{\mathrm{d}}=15.05 \mathrm{kN} / \mathrm{m}^{3}$. The initial degree of saturation was $59,24 \%$ which corresponds to a suction of $5.0 \mathrm{MPa}$. The different sample values of water content are presented in table 1, besides other data corresponding to each water content value.

Table 1. Influence of initial water content

\begin{tabular}{ccccc}
\hline $\mathrm{w}(\%)$ & $\mathrm{s}(\mathrm{MPa})$ & $\mathrm{S}(\%)$ & $\mathrm{e}$ & $\gamma_{\mathrm{d}}\left(\mathrm{KN} / \mathrm{m}^{3}\right)$ \\
\hline 7.76 & 117.0 & 35.22 & 0.597 & 16.96 \\
17.41 & 5.0 & 59.24 & 0.801 & 15.05 \\
20.70 & 0.7 & 63.39 & 0.885 & 14.37 \\
22.60 & 0.2 & 65.43 & 0.936 & 14.00 \\
\hline
\end{tabular}

In the oedometric tests carried out the sample was flooded under a low vertical stress value $(10 \mathrm{kPa})$ and swelling deformation was measured, then the specimen was loaded in stages, with a ratio of loading $\Delta \sigma_{v} / \sigma_{v}=1$, up to a vertical pressure of $1280 \mathrm{kPa}$. The stressstrain curves from the tests are shown in figure 3.

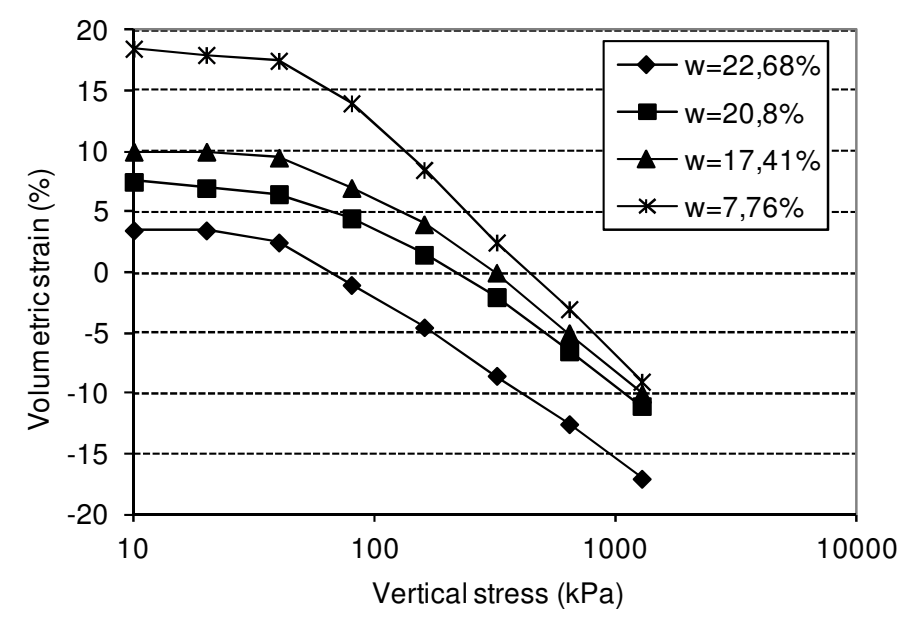

Figure 3. Influence of initial water content in swelling. 
The data presented in table 1 show that water content variation changes not only suction (s) and degree of saturation (S) but also void ratio (e) and dry density $\left(\gamma_{\mathrm{d}}\right)$. Thus the samples should present some different parameters values.

The parameters used in the simulation were obtained from tests results and are listed in Table 2. The interaction functions are the same for all the tests.

Table 2. Parameters used in the simulation

\begin{tabular}{|c|c|c|c|c|}
\hline Parameter & $\mathrm{W}=7.76 \kappa_{\mathrm{f}}$ & $\mathrm{w}=17.41$ & $\mathrm{w}=20.70$ & $\mathrm{w}=22.60$ \\
\hline \multicolumn{5}{|l|}{ Macrostructure } \\
\hline$\kappa$ & 0.01 & 0.01 & 0.01 & 0.01 \\
\hline$\kappa_{s}$ & 0.002 & 0.002 & 0.002 & 0.002 \\
\hline$\lambda(0)$ & 0.12 & 0.10 & 0.08 & 0.08 \\
\hline$r$ & 0.50 & 0.50 & 0.50 & 0.50 \\
\hline$\beta\left(\mathrm{MPa}^{-1}\right)$ & 1.00 & 1.00 & 1.00 & 1.00 \\
\hline$p_{0} *(\mathrm{MPa})$ & 0.26 & 0.20 & 0.16 & 0.08 \\
\hline$p^{c}(\mathrm{MPa})$ & 0.10 & 0.10 & 0.10 & 0.10 \\
\hline \multicolumn{5}{|l|}{ Microstructure } \\
\hline$\alpha_{m}\left(\mathrm{MPa}^{-1}\right)$ & 0.045 & 0.006 & 0.001 & 0.001 \\
\hline$\beta_{m}\left(\mathrm{MPa}^{-1}\right)$ & 0.005 & 0.013 & 0.07 & 0.08 \\
\hline$\chi$ & 1.0 & 1.0 & 1.0 & 1.0 \\
\hline \multicolumn{5}{|l|}{ Initial void ratio } \\
\hline $\mathrm{e}_{\text {macro }}$ & 0.597 & 0.801 & 0.885 & 0.936 \\
\hline $\mathrm{e}_{\text {micro }}$ & 0.10 & 0.30 & 0.35 & 0.38 \\
\hline \multicolumn{5}{|l|}{ Interaction functions } \\
\hline
\end{tabular}

Laboratory data and the numerical simulation results are presented in figures 4 and 5 . According to the double structure model applied a decrease in suction implies a microstructural swelling (figure 1). For a constant stress level, the higher the initial suction, the greater the swelling due to flooding, which was observed in the tests carried out (figures 4 and 5).
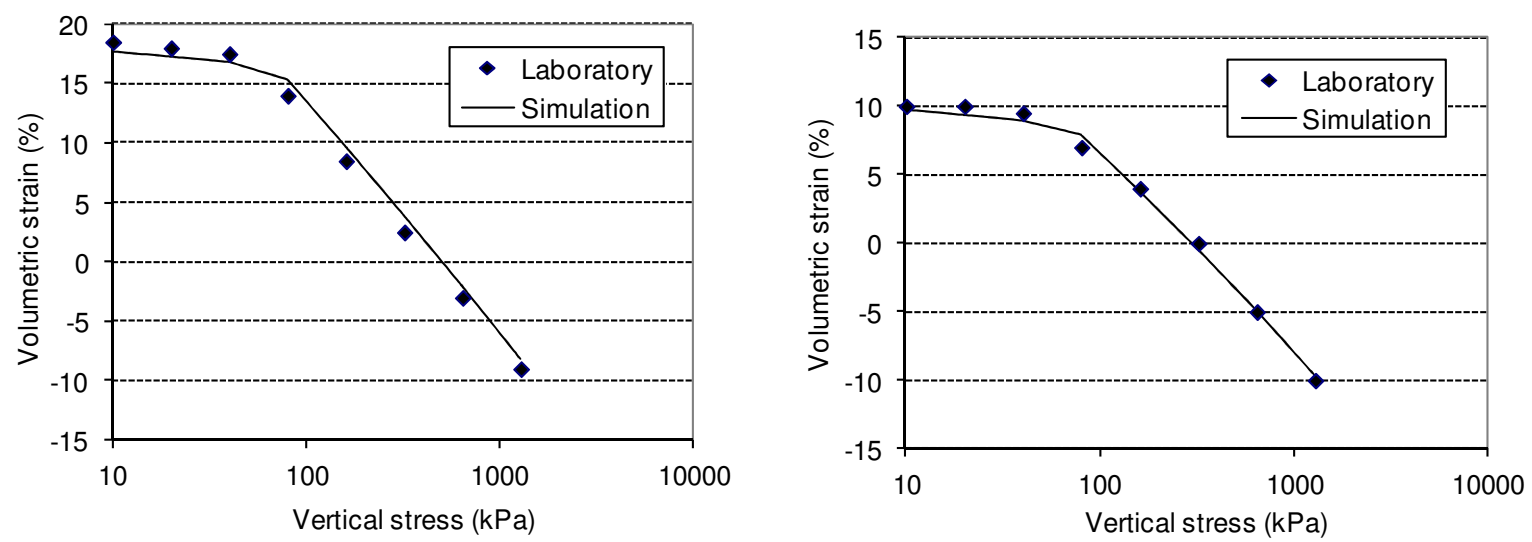

Figure 4. Comparison between laboratory data and simulation results: a) initial water content, $\mathrm{w}=7.76 \%$; b) initial water content, $\mathrm{w}=17.41 \%$. 

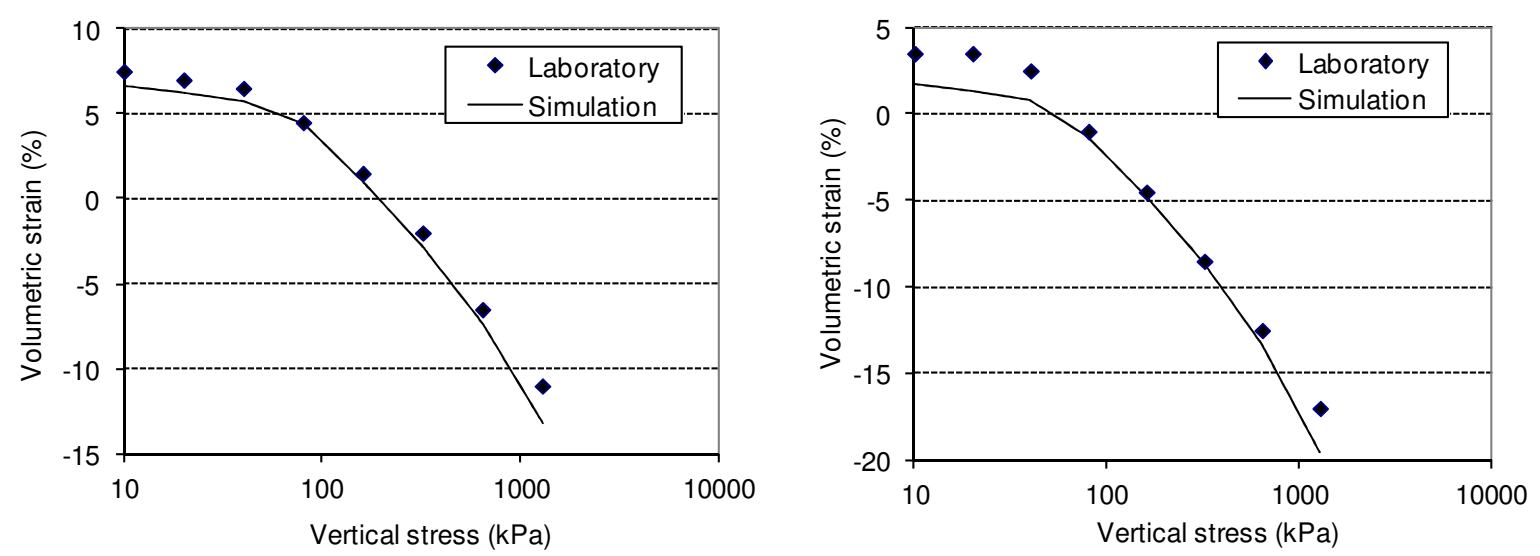

Figure 5. Comparison between laboratory data and simulation results: a) initial water content, $\mathrm{w}=20.70 \%$; b) initial water content, $\mathrm{w}=22.60 \%$.

A good agreement is observed between experimental data and simulation results. The swelling deformations measured were well reproduced by the model, besides the volumetric strains due to loading. Just the last test, at highest initial water content, presents a significant difference for the amount of swelling.

\section{CONCLUSIONS}

According to the results herein presented by the numerical simulation carried out, it is demonstrated the capability of the double structure model and the computer code to reproduce the hydro-mechanical behavior of expansive soils. It should also be highlighted the influence of the value of initial water content of the soil for predicting the amount of swelling deformation.

\section{Acknowledgements}

The authors wish to thank the financial support provided by $\mathrm{CNPq} / \mathrm{Brazil}$.

\section{REFERENCES}

[1] Alonso, E. E.,Gens, A. \& Josa, A. 1990. A constitutive model for partially saturated soils. Geotechnique, vol. 40, nº 3, pp. 405-430.

[2] Alonso E, Vaunat J, Gens A. 1999. Modelling the mechanical behaviour of expansive clays. Engineering Geology, vol. 54, pp. 173-183.

[3] Ferreira, S. R. M. \& Ferreira, M. G. V. X. 2009 Mudanças de volume devido à variação do teor de umidade em um vertissolo no semi-árido de Pernambuco. Revista Brasileira de Ciência do Solo, v. 33, pp. 779-791. 
[4] Gens A., Alonso E. E. 1992. A framework for the behaviour of unsaturated expansive clays. Canadian Geotechnical Journal; vol. 29, pp. 1013-1032.

[5] Sanchez, M., Gens A., Guimarães, L. N. \& Olivella, S. 2005. A double structure generalized plasticity model for expansive materials, Int. J. Numer. Anal. Meth. Geomech.; vol. 29, pp.751-787. 